\title{
Placental Anthropometric Features: Maternal and Neonate Characteristics in North Central Nigeria
}

\author{
Adam Moyosore Afodun, Moyosore Salihu Ajao, and Bernard Ufuoma Enaibe \\ Department of Anatomy, Faculty of Basic Medical Sciences, College of Health Sciences, University of Ilorin, \\ PMB 1515, Ilorin 240003, Nigeria
}

Correspondence should be addressed to Adam Moyosore Afodun; afodunadam@yahoo.com

Received 19 May 2015; Accepted 27 July 2015

Academic Editor: Huayue Chen

Copyright (C) 2015 Adam Moyosore Afodun et al. This is an open access article distributed under the Creative Commons Attribution License, which permits unrestricted use, distribution, and reproduction in any medium, provided the original work is properly cited.

The objectives of the study were to determine placental weight as well as factors associated with low placental weight and to determine its impact on some anthropometrical parameters in the newborn. A total of 300 freshly delivered placentas were examined in this longitudinal-prospective study. Sobi Specialist Hospital, Alagbado, Ilorin, and Surulere Medical Centre, Eruda, Ilorin, were used for sample collections. Informed consent was obtained from patients and institutional ethical clearance was obtained from Kwara State Ministry of Health (MOH/KS/ECI/777/82). Semistructured questionnaire was used to gather data on the patients and newborns demographic indices. Analysis of variance, Student's $t$-test, regression analysis, and Pearson moment correlation statistical analysis were employed to analyze the data. The mean wet placental weight for normal pregnancies was $529 \mathrm{~g}$ $(\mathrm{SD}=84.01)$. Placental weight to birth weight ratio of $1: 5.83$ was generated, $529 \mathrm{~g}$ impact on newborn head circumference (mean: male $=35.30 \mathrm{~cm}$, female $=34.90 \mathrm{~cm}$ ) having a linear correlation. Regression analysis showed negative association between female babies $(2.99 \mathrm{~kg})$ placental weight $(r=0.369 ; P \leq 0.05)$, birth weight, and cord length (mean $=58.4 \mathrm{~cm})$. Placental weight correlation with male newborn weight $(3.14 \mathrm{~kg})$ had placental birth weight ratio of 0.679 between 90 th and 10 th percentile $P<0.05$ with head circumference $(r=0.473, P<0.05)$, lower limit placental diameter $22.80 \pm 1.76 \mathrm{~cm}(\mathrm{SD}=4.8), \mathrm{BMI} \leq 19.50$, and Apgar score of $7 / 10$. It is concluded that blood holding capacity of the placenta (relative to weight) and the maternal-dietary have influence on placental weight. Differences in hormonal environment in utero and pathologic adaptation of placenta, due to racial factors, significantly contributed to the size of newborn baby.

\section{Introduction}

The placenta is the vital organ for promoting and maintaining pregnancy and normal fetal development [1]. It is elaborated by both fetal and maternal tissues to serve as an instrument for essential nutrient transfer. Researchers have, for a long time, emphasized the benefits which are associated with the anatomical examination of the placenta, an organ that is often disposed soon after parturition, without adequate examination.

Intimate association between embryo and mother in placental mammals creates the potential problem of two genetically distinct individuals having to coexist for the duration of pregnancy [2]. Term placenta is about $23 \mathrm{~cm}$ in diameter and 2.0 to $2.6 \mathrm{~cm}$ thick. It generally weighs approximately $470 \mathrm{~g}$, with an average volume of $500 \mathrm{~mL}$ [3].
The ratio between placental weight and newborn weight has been reported as 1:6 [3]. Measurements vary widely and considerably in different regions [4]. It has been shown that fetal or maternal diseases (severe anaemia, hypertension, and fetal hydrops) influence fetal and placental weight $[5,6]$.

Placental weight has a significant role in fetal growth in terms of cord length, body length, and neonate abdominal circumference but it had no significant role in the presence of excessive meconium stained tissues [7]. While some other studies have shown less correlation between mentioned factors and placental weights, Addai and Ockleford [8] and Little et al. [9] showed that absolute measures of infant size and placental weight had mutual positive correlation. In another observation by Agboola, presence of low hematocrit was associated with higher placental weight and lower fetal weight [10]. 
Bortolus et al. [11] have shown that pregnancies with induced hypertension result in high weight placentas, contrary to the findings of Lao et al. who found no significant differences in placental weight or birth weight between neonates with absence or presence of meconium stained amniotic fluid $[12,13]$.

There are placenta findings that may lead to counseling or clinical intervention in or before future pregnancies. Other observations are believed to be due to abnormal immune response maternally "rejecting" the placental allograft [14]. The maternal surface is finely granular, mapped into 18-25 lobes by grooves or fissures (lobes) corresponding in large measure to the major branches of distribution of the umbilical vessels [15]. Fetal surface is covered by amnion with the umbilical cord attached to its center [16].

Information from gross placental description can be critical in early neonatal care, in reproductive planning for the family, and it can provide risk assessment for neurologic outcome of the infant [17]. The results of this study would have an important implication for infant care and decision making for obstetrics. Lesions of the placenta often explain or reflect the condition in which the neonate was born and some have histopathological implications.

Anthropometrists for a long time have emphasized the benefits which are associated with the anatomic examination of the placenta, an organ that is often disposed soon after parturition without adequate observation. Examination of the placenta in utero as well as postpartum gives valuable information about the state of the fetal well-being [18].

Recent studies indicate that altered growth of the placenta could be a predictor of adult onset diseases including hypertension and cardiovascular disease $[19,20]$. A large placenta and a low birth weight are particularly strong independent risk factors.

\section{Materials and Method}

This cross-sectional study was carried out at the Obstetric and Gynaecological Department/Labour Room of the Sobi Specialist Hospital (SSH), Alagbado, Ilorin, and Surulere Medical Center (SMC), Ilorin.

2.1. Reliability of Placenta Anthropometry. To ensure credibility of placenta measurement, the morphometrist performed a pilot study at SMC, Ilorin (with 100 respondents), at least 4 months from the initial measurement to eliminate the potential for familiarity or recognition.

Criteria used were the same as those of the main experiment. Intraclass correlation coefficient was around 0.1 . Precoded (closed) questionnaires with a range of alternative answers are provided to patients.

Respondent's answers are expected to be among any of the exclusive categories. However, a blank option of "others" is allowed to indicate answers not in the ones mentioned.

2.2. Sample Population. Our safety limit is to take a sample that is truly representative in all aspects of the (placental) parent population by attempting to (a) tolerate minimal errors and (b) avoid bias.
The placenta sampling plan is designed to give every possible variant of a given size an equal chance of being selected. A power analysis is generally used to determine an appropriate sample size, but in some cases the sample size is fixed and the aim would be to determine power [21].

2.3. Sample Size Determination. In the mathematical process of deciding before a study begins how many subjects should be studied [22]? This protocol is based on a structured sampling technique. It is unbiased with consideration for level of significance, possible type I and type II errors, hypothesis testing, and power analysis.

Equation for cross-sectional study:

$$
n=\frac{Z^{2} p q}{d^{2}}
$$

where $n=$ minimum sample size and $Z=$ the standard normal variate (at 5\%) which is 1.96 . $p$ is prevalence of what is being sort in a previous study, that is, similar/expected proportion in population based on previous studies (research on placental and cord parasitaemia $[23,24], p \approx 20 \%$ ) (if no reliable data exists, the value of 0.5 is used), $q=1-p$, and $d=$ precision, determined by the researcher. 0.05 is usually used [25].

Thus

$$
n=\frac{1.96^{2} \times 0.2(1-0.2)}{0.05^{2}} \quad n=245 \text { placenta samples. }
$$

2.4. Instruments of Data Collection. Instruments used in data collection are as follows:

(i) Analogue way master (England; CMS Weighing Equipment Ltd., London).

(ii) Flexible (nonstretchable) measuring tape [26] Lasso butterfly (Guangzhou, China).

(iii) Disposable gloves and flash light.

(iv) Stainless steel kidney dish.

(v) Digital camera: general electric model number AF30, 10x zoom magnification.

(vi) Theatre boots, face masks, and cotton wool.

(vii) Laboratory coat, disinfectant, and deodorant.

(viii) Ligature (Nylon 2.0).

2.5. Ethical Consideration of the Study. The Kwara State Ministry of Health Ethical Review Committee, Fate, Ilorin, approved the present study in line with the 1964 Helsinki Declaration.

2.6. Placental Weighing and Preparation. The placentas were weighed and examined according to the method of Benirschke et al. [27]. This does not involve trimming the disc membrane or umbilical cord.

APGAR scores were recorded at 1 and 10 minutes. The placentas were collected soon after their expulsion from both cesarean sections and normal deliveries. No trimming of placenta membrane was carried out. 
2.7. Anthropometric Measurement of the Newborn. Neonates whose placentas were utilized were examined for some of the following parameters:

(i) Weight of the baby.

(ii) Sex of the baby.

(iii) Head circumference.

(iv) Maturity of the newborn.

(v) Congenital anomalies (if present).

2.8. Measurement of Neonate Head Circumference (HC). Newborn occipitofrontal circumferential measurement is a simple procedure which may be the first clue to an underlying problem. Growth measurements encompass head circumference and weight [28].

A flexible nonstretchable measuring tape (Lasso, Guangzhou, China) was used [26]. Head circumference or OFC (occipital frontal circumference) was measured over the most prominent part on the head (occiput) and just above (superior to) the eyebrows (supraorbital ridges) according to the procedure of Fry [29]. That is translated to mean the largest head circumference. After 3 measurements per head the gloves were immediately discarded to minimise the risk of cross infection.

Abnormal rate of head growth could suggest a pathological disorder requiring diagnosis and treatment, for example, craniosynostosis, microcephaly, and hydrocephalus [30, 31]. The aim of measuring a head circumference is to monitor growth of child, particularly those under 2 years [29].

2.9. Statistical Analysis. All statistical analysis was performed using Microsoft Statistical Package for Social Sciences (SPSS) software version 19.0, Chicago Inc. Student's $t$-test was used to assess normally distributed variables. Numerical variables were expressed as mean \pm standard deviation; $P<0.05$ was considered significant [32].

\section{Result}

Some neonatal and maternal features and other demographic variables are shown in Table 1 . In this study, the average wet placental weight is $529 \mathrm{~g}(\mathrm{SD}=119)$ while the average dry placental weight is $432 \mathrm{~g}(\mathrm{SD}=102)$ (Table 2$)$.

Armitage et al. [33] reported the average weight of the placenta to be $508 \mathrm{~g}$ and the present study showed an average placental weight of $529 \mathrm{~g}(0.529 \mathrm{~kg})$. This could possibly be due to racial differences, improvement in the antenatal care, and nutritional status of the mother. Pearson moment correlation coefficient $r=0.468, P<0.005$.

Placental weight increased according to the birth weight and was shown to be statistically significant. Neonates and babies from multiparous women from 37 weeks onwards were heavier than those from primiparous women. There is a slight increase in mean placental weight with increasing parity with a reduction at parity of 3 and above (Table 1).

There was significant correlation between short umbilical cords $(<30 \mathrm{~cm})$ (Table 3$)$ and premature separation of placenta from the wall of the uterus during delivery.
TABLE 1: Showing some neonate and maternal features.

\begin{tabular}{|c|c|}
\hline Feature/characteristic & Number $300(\%)$ \\
\hline \multicolumn{2}{|l|}{ (A) Birth weight (g) } \\
\hline$<2,500$ & $36(12)$ \\
\hline $2500-4000$ & $243(81)$ \\
\hline$>4000$ & $21(7)$ \\
\hline \multicolumn{2}{|l|}{ (B) Maternal age (yrs) } \\
\hline$<20$ & $63(21)$ \\
\hline$\geq 35$ & $33(11)$ \\
\hline $20-35$ & $204(68)$ \\
\hline \multicolumn{2}{|l|}{ (C) Ethnicity (race) } \\
\hline Negroid & $298(99)$ \\
\hline Yoruba & $216(72)$ \\
\hline Igbo & $24(8)$ \\
\hline Hausa/Fulani & $45(15)$ \\
\hline Other & $15(5)$ \\
\hline \multicolumn{2}{|l|}{ (D) Mothers education } \\
\hline Graduate & $27(9)$ \\
\hline Secondary school & $69(23)$ \\
\hline Primary school & $36(12)$ \\
\hline Illiterate & $168(56)$ \\
\hline \multicolumn{2}{|l|}{ (E) Parity } \\
\hline Nulliparous & $48(16)$ \\
\hline$>1$ previous birth & $222(74)$ \\
\hline 1 previous birth & $30(10)$ \\
\hline Multiparous & $252(84)$ \\
\hline \multicolumn{2}{|l|}{ (F) Gestational age at birth } \\
\hline 38 wks (<40 wks) (preterm) & $72(24)$ \\
\hline (40 wks TERM) & $213(71)$ \\
\hline $42 \mathrm{wks}$ (>40 wks) postdate & $15(5)$ \\
\hline \multicolumn{2}{|l|}{ (G) Route of delivery } \\
\hline $\begin{array}{l}\text { ND (normal delivery)/SVD (spontaneous } \\
\text { vaginal delivery) }\end{array}$ & $207(69)$ \\
\hline Caesarean section (including transverse lie) & $72(24)$ \\
\hline \multicolumn{2}{|l|}{ (H) Others } \\
\hline (Manual-breech assisted manipulation) & $3(1)$ \\
\hline Vacuum extraction & $3(1)$ \\
\hline Forceps extraction & $15(5)$ \\
\hline
\end{tabular}

No case of triplets was recorded throughout the period of study. Placentas of twin pregnancy (12/300) were examined for zygosity and vascular anastomosis.

Maternal height did not show positive correlation with placental weight. $72.5 \%$ of women were between 19 and 32 years of age. The rate for cesarean section was $24 \%$. $49.3 \%$ of the subjects had a normal body mass index. Emergency and referral to neonatal intensive care unit NICU admission was required in about $16 \%$ of cases (Table 3 ).

More high weight placentas were recorded in the 2035-year age group, while most low weight was noted with women less than 20 years (Table 1). Lower Apgar scores 
TABLE 2: Showing placental description of the study population.

\begin{tabular}{|c|c|c|c|}
\hline Description/variable & Range & Mean & SD \\
\hline Placental weight (wet) & $1,050-396$ & 529 & 119 \\
\hline Placental weight (dry) & $670-102$ & 432 & 102 \\
\hline $\begin{array}{l}\text { Standard deviation of } \\
\text { chorionic plate radius }\end{array}$ & $2.3-53$ & 9.7 & 6.1 \\
\hline Major axis $(\mathrm{cm})$ & $12-41$ & 21.8 & 3.3 \\
\hline \multirow[t]{2}{*}{ Minor axis $(\mathrm{cm})$} & 8-28 & 17.6 & 2.5 \\
\hline & Adjusted $r^{2}$ & $r^{2}$ change & $P$ value \\
\hline $\begin{array}{l}\text { Placental weight (dry) } \\
\text { (term }>40 \text { weeks GA) }\end{array}$ & 0.35 & 0.03 & 0.18 \\
\hline $\begin{array}{l}\text { Placental weight }(\text { dry) } \\
\text { (preterm }<40 \text { weeks GA) }\end{array}$ & 0.67 & 0.03 & 0.006 \\
\hline
\end{tabular}

corresponded to low weight placenta, which correlated with more cesarean sections, increased fetal distress, and abnormal weight fluctuation (Table 3).

Cases of advance maturation were associated with meconium stained membranes; increased placental calcification and slightly larger $(>35.4 \mathrm{~cm})$ and more oval head circumference findings correlated with study by Burgess and Hutchins [34].

The present study revealed an average birth weight of $3.06 \mathrm{~kg}$ and a neoplacental ratio of 5.8. Better anthropometric measurements would not only improve our ability to detect interindividual differences in intrauterine experience but also provide an anatomically grounded method to capture the fetal growth experience.

\section{Discussion}

Mean placental weight from spontaneous vaginal deliveries was $81 \mathrm{~g}$ lighter than those from cesarean sections. Burkhardt et al. [35] however estimated $76 \mathrm{~g}$ difference in weight.

Since placental weight has a relationship with neonate weight, there should be a positive correlation between placental weight and infant sex [7]. Contrarily, we found no correlation probably due to environmental, genetic, or ethnic factors. Ratio of women with high placental weight who had cesarean section to women with natural vaginal delivery was $4.8: 1.7$. This ratio was $4.0: 0.4$ for low placental weight. The prevalence of high and low weight placentas in fetuses under distress was $3.2 \%$ and $7.4 \%$, respectively.

Factors influencing placental weight include gestational age. Kinare et al. [36] stated that the capacity of fetal growth is determined by placental growth. One of the major nutrient transport functions of the placenta is to ensure adequate transfer of glucose to the fetus from maternal circulation. Nutrient and glucose transport across the placental barrier is crucial for fetal development. A common feature of pregnancies with IUGR is relative fetal hypoglycemia, and a small placenta per se is the major limitation of placenta glucose transfer to the unborn.

Others such as Molteni et al. [37] proved that placental weight is related to gestational age. In our study, the placental weight ratio PWR and normal placental weight distribution curve for terminal gestational ages were constructed.

Similarly, PWR and deviated placental weight with certain adverse postnatal outcome caused reduction in PWR with ascending gestational age as expressed in this study which is in agreement with Altman et al. [38] and Dombrowski et al. [39].

Prevalence of high and low weight placentas from cesarean section labors was more than from normal vaginal labors. This corresponded with APGAR score decline and general fetal distress. Placental ratio tended to rise/increase from the microsomic to the macrosomic divisions for patients with uncomplicated pregnancies and with gravidae complicated by pregnancy-induced hypertensions or IUGR, in agreement with Thame et al. [5]. It is suggested that dry weight of placenta relative to birth weight and placental wet weight relative to newborn weight are exchangeable due to their high correlation. A similar study by Leary et al. [40] confirmed this finding.

The results of the present study show normal placental weight at term and also reveal that placental weight increases are associated with rise in birth weight (in normal pregnancy).

Placental weight increases in neonates geometrically (proportionately) with gestational age and descends with order of parity.

Results show PWR may be affected by various ethnicity and other unknown factors. Not only is the prevalence of high placental weight higher in preeclampsic women but low placental weight prevalence in preeclampsia is also higher than normal uncomplicated pregnancies. Average placental weight showed significant increase from microsomic to largefor-gestational age (LGA). One of the main factors for this problem is function seeming to depend on the reverse capacity of the placenta. Our data was similar to Lo et al.'s [7] study.

\section{Conclusion}

This study has shown the positive link between neonate weight and placental weight. Moreover, the ratio of placental fetal weights at term decreases with advancing gestational age. Therefore, prolongation of pregnancy at 40 weeks (term) may adversely affect the fetus.

The present study showed that skewed placental weight (at $<10$ percentile) correlated with neonate weight. The advent of sophisticated medical imaging modalities like Colour Doppler Imaging (CDI) and adequate knowledge of anthropometric features of the placenta with its clinical relevance proves to be useful in the early assessment of placental sufficiency and state of fetal health.

Generally, it seems that with documented clinical history relevant anatomic structural derivation from questionnaire and denominating placental weight ratio may predict adverse outcomes. Further research is needed to confirm such associated relevance.

The excellent reproducibility of our anthropometric measures is likely to yield valid estimates of placental associations with gestational age parity (order of pregnancy) and birth weight that may clarify the complex interrelations among 
TABLE 3: Showing placental diameter, Apgar score, and cord length.

\begin{tabular}{|c|c|c|c|}
\hline Data & Control normal pregnancy & Microsomic cases & $P$ value \\
\hline Apgar score (mean) 5 (mins) & $9.5 \pm 0.7$ & $7.2 \pm 2.9$ & 0.000 \\
\hline Average placental weight (g) & 529 & $311 \pm 48$ & 0.000 \\
\hline Umbilical cord length $(\mathrm{cm})$ & $53.1 \pm 22.6$ & $24.8 \pm 1.0$ & 0.000 \\
\hline Placental diameter $(\mathrm{cm})$ & $17.3 \pm 1.6$ & $14.1 \pm 2.53$ & 0.000 \\
\hline Parameter & Number & $\%$ (percentage) & $P$ value \\
\hline \multicolumn{4}{|l|}{ Apgar at 5 mins } \\
\hline$\leq 6$ & 5 & 1.6 & $<0.05$ \\
\hline$>6$ & 295 & 98.4 & $<0.05$ \\
\hline \multicolumn{4}{|l|}{ Incubation/NICU } \\
\hline No & 284 & 94.6 & $<0.05$ \\
\hline Yes & 16 & 5.4 & $<0.05$ \\
\hline
\end{tabular}

placenta, mother, and fetus to maintain pregnancy and support fetal development.

\section{Recommendations}

The following are recommended:

(i) Ultrasonic inspection and follow-up of placenta growth in early pregnancy should be done, as this will prevent risks to fetal life and improve newborn health.

(ii) Prompt anatomic placental interpretation should be carried out on ill mothers and babies before referral to pathologists.

(iii) In multiple (twin) dichorionic placentas it is recommended that they are separated (if fused) to account for incidental findings such as vanishing twin phenomenon.

(iv) We suggest that clinicians, pathologists, and radiologists should try to identify abnormally shaped placenta at the earliest stage, so that any structural complications can be (possibly) treated hence reducing mortality and morbidity rate.

\section{Conflict of Interests}

The authors declare that there is no conflict of interests regarding the publication of this paper.

\section{References}

[1] F. K. Addai, "Association of histologic component volumes of shed human placentae with placental index and gestational age of neonates, and haemoglobin genotype of mothers," West African Journal of Anatomy, vol. 5, pp. 21-22, 1997.

[2] D. R. J. Bainbridge, "Evolution of mammalian pregnancy in the presence of the maternal immune system," Reviews of Reproduction, vol. 5, no. 2, pp. 67-74, 2000.

[3] F. G. Cunningham, K. J. Leveno, S. L. Bloom, J. C. Hauth, L. C. Gilstrap III, and K. D. Wenstrom, "Implementation, embryogenesis and placental development," in Williams Obstetrics, McGraw-Hill, New York, NY, USA, 22nd edition, 2005.
[4] J. F. Yetter III, "Examination of the placenta," American Family Physician, vol. 57, no. 5, pp. 1045-1054, 1998.

[5] M. Thame, C. Osmond, R. J. Wilks, F. I. Bennett, N. McFarlaneAnderson, and T. E. Forrester, "Blood pressure is related to placental volume and birth weight," American Journal of Family Physicians, vol. 2, no. 1, article 168, 1998.

[6] S. Heinonen, P. Taipale, and S. Saarikoski, "Weights of placentae from small-for-gestational age infants revisited," Placenta, vol. 22, no. 5, pp. 399-404, 2001.

[7] Y.-F. Lo, M.-J. Jeng, Y.-S. Lee, W.-J. Soong, and B. Hwang, "Placental weight and birth characteristics of healthy singleton newborns," Acta Paediatrica Taiwanica, vol. 43, no. 1, pp. 21-25, 2002.

[8] F. K. Addai and C. D. Ockleford, "A study of placental component volumes in maternal sickle cell disease," West African Journal of Anatomy, vol. 4, pp. 1-6, 1996.

[9] R. E. Little, T. D. Zadorozhnaga, O. P. Hulchiy et al., "Placental weight and its ratio to birthweight in a Ukrainian city," Early Human Development, vol. 71, no. 2, pp. 117-127, 2003.

[10] A. Agboola, "Placental changes in patients with a low haematocrit," BJOG, vol. 82, no. 3, pp. 225-227, 1975.

[11] R. Bortolus, L. Chatenoud, E. Di Cintio et al., "Placental ratio in pregnancies at different risk for intrauterine growth," European Journal of Obstetrics Gynecology and Reproductive Biology, vol. 80, no. 2, pp. 157-158, 1998.

[12] T. T. Lao and W. M. Wong, "Implications of a high placental ratio in pregnancies with appropriate-for-gestational age neonates," Gynecologic and Obstetric Investigation, vol. 52, no. 1, pp. 34-37, 2001.

[13] F. K. Addai, F. J. K. Quashie, and C. D. Ockleford, "The mode of insertion of umbilical cord and vessels: association with maternal haemoglobin genotype, neonatal factors, and placental component volumes," Anatomy and Embryology, vol. 189, no. 2, pp. 107-114, 1994.

[14] I. Adams-Chapman, Y. E. Vaucher, R. F. Bejar, K. Benirschke, R. N. Baergen, and T. R. Moore, "Maternal floor infarction of the placenta: association with central nervous system injury and adverse neurodevelopmental outcome," Journal of Perinatology, vol. 22, no. 3, pp. 236-241, 2002.

[15] S. Strandring, Ed., Gray's Anatomy: The Anatomical Basis of Clinical Practice, E-Version, Churchill-Livingstone (Elsevier), London, UK, 39th edition, 2005.

[16] K. L. Moore and T. V. N. Persuad, Clinically Oriented Embryology, Elsevier, New York, NY, USA, 8th edition, 2010. 
[17] D. J. Roberts, "Placental pathology, a survival guide," Archives of Pathology and Laboratory Medicine, vol. 132, no. 4, pp. 641-651, 2008.

[18] K. Kouvalainen, A. L. Pynnönen, M. Mäkäräinen, and T. Peltonen, "Weights of placenta, fetal membranes and umbilical cord," Duodecim, vol. 87, no. 17, pp. 1210-1214, 1971.

[19] D. J. P. Barker, A. R. Bull, C. Osmond, and S. J. Simmonds, "Fetal and placental size and risk of hypertension in adult life," British Medical Journal, vol. 301, no. 6746, pp. 259-262, 1990.

[20] F. K. Addai, The Human Placenta: Why the Afterbirth Must Not Be an Afterthought, College of Health Sciences Seminars 2001 Series, Korle-Bu, Accra, Ghana, 2001.

[21] D. G. Altman, "Statistics in medical journals," Statistics in Medicine, vol. 1, no. 1, pp. 59-71, 1982.

[22] J. M. Last, Ed., A Dictionary of Epidemiology, Oxford University Press, Oxford, UK, 1995.

[23] O. M. Kolawole, A. S. Babatunde, A. A. G. Jimoh, O. R. Balogun, and I. G. Kanu, "Risk determinants to congenital malaria in Ilorin, Nigeria," Asian Journal of Microbiology, Biotechnology \& Environmental, vol. 12, no. 2, pp. 215-222, 2007.

[24] E. L. Ikeh, S. Akudo, and V. Uguru, "Prevalence of malaria parasitaemia in pregnant women attending antenatal clinic at Jos University Teaching Hospital," African Journal of Clinical and Experimental Microbiology, vol. 6, no. 2, pp. 91-92, 2005.

[25] C. M. Varkerisser and A. Browlee, Designing and Conducting Health Systems Research Projects, Proposal Development and Fieldwork, Module 11, WHO/International Development Research, 2003.

[26] J. L. Bartram, A. S. Rigby, and P. S. Baxter, “The 'Lasso-o' tape: stretchability and observer variability in head circumference measurement," Archives of Disease in Childhood, vol. 90, no. 8, pp. 820-821, 2005.

[27] K. Benirschke, P. Kaufmann, and R. N. Baergen, Pathology of the Human Placenta, Springer Science+Business Media, New York, NY, USA, 2006.

[28] S. Schlig and T. Hulse, Growth, Monitoring and Assessment in the Community: A Guide to Good Practice, Child Growth Foundation, London, UK, 1997.

[29] T. Fry, "Introducing the new child growth standards," Professional Care of Mother and Child, vol. 4, no. 8, pp. 231-233, 1994.

[30] R. W. Block, N. F. Krebs, R. A. Hibbard et al., "Failure to thrive as a manifestation of child neglect," Pediatrics, vol. 116, no. 5, pp. 1234-1237, 2005.

[31] L. May, Hydrocephalus and Neurosurgery - A Handbook for the Multidisciplinary Team, Whurr Publishers, London, UK, 2000.

[32] B. K. Mahayan, Significance of Difference in Mean. Methods in Biostatistics for Medical Andresearch Workers, JAPEE Brothers Medical Publishers, New delhi, India, 6th edition, 1997.

[33] P. Armitage, J. D. Boyd, W. J. Hamilton, and B. C. Rowe, "A statistical analysis of a series of birth weights and placental weight," Human Biology, vol. 39, no. 4, pp. 430-444, 1967.

[34] A. M. Burgess and G. M. Hutchins, "Inflammation of the lungs, umbilical cord and placenta associated with meconium passage in utero: review of 123 autopsied cases," Pathology Research and Practice, vol. 192, no. 11, pp. 1121-1128, 1996.

[35] T. Burkhardt, L. Schäffer, C. Schneider, R. Zimmermann, and J. Kurmanavicius, "Reference values for the weight of freshly delivered term placentas and for placental weight-birth weight ratios," European Journal of Obstetrics Gynecology and Reproductive Biology, vol. 128, no. 1-2, pp. 248-252, 2006.
[36] A. S. Kinare, A. S. Natekar, M. C. Chinchwadkar et al., "Low midpregnancy placental volume in rural Indian women: a cause for low birth weight?" The American Journal of Obstetrics and Gynecology, vol. 182, no. 2, pp. 443-448, 2000.

[37] R. A. Molteni, S. J. Stys, and F. C. Battaglia, "Relationship of fetal and placental weight in human beings: fetal/placental weight ratios at various gestational ages and birth weight distributions," Journal of Reproductive Medicine, vol. 21, no. 5, pp. 327-334, 1978.

[38] D. G. Altman, J. M. Bland, L. Meyer, A. Leyland, and C. Pritchard, "Fetal growth and ratio of placental weight to birth weight," British Medical Journal, vol. 304, no. 6833, pp. 10521053, 1992.

[39] M. P. Dombrowski, S. M. Berry, M. P. Johnson, A. A. A. Saleh, and R. J. Sokol, "Birth weight-length ratios, ponderal indexes, placental weights, and birth weight-placenta ratios in a large population," Archives of Pediatrics and Adolescent Medicine, vol. 148, no. 5, pp. 508-512, 1994.

[40] S. D. Leary, K. M. Godfrey, L. J. Greenaway, V. A. Davill, and C. H. D. Fall, "Contribution of the umbilical cord and membranes to untrimmed placental weight," Placenta, vol. 24, no. 2-3, pp. 276-278, 2003. 

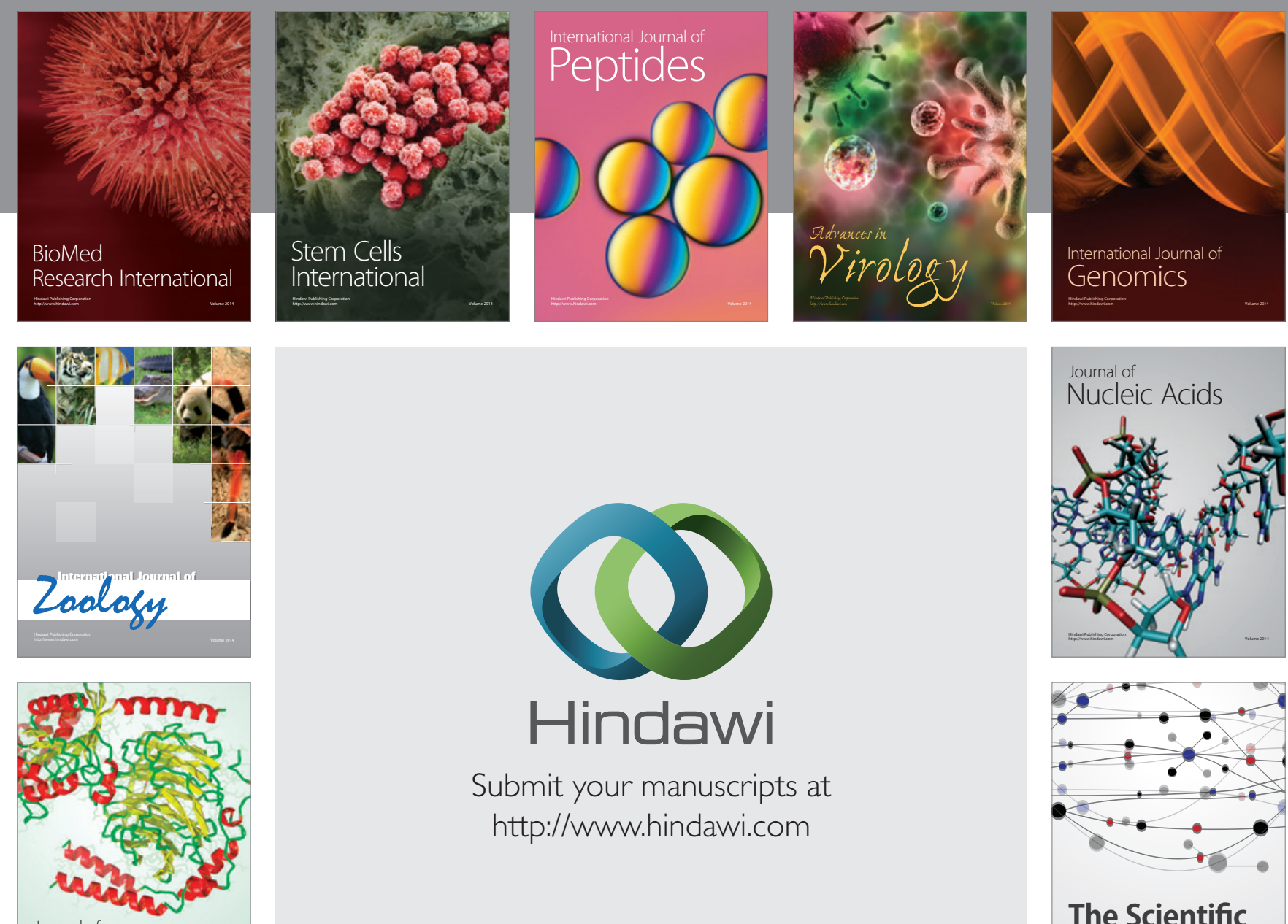

Submit your manuscripts at

http://www.hindawi.com

Journal of
Signal Transduction
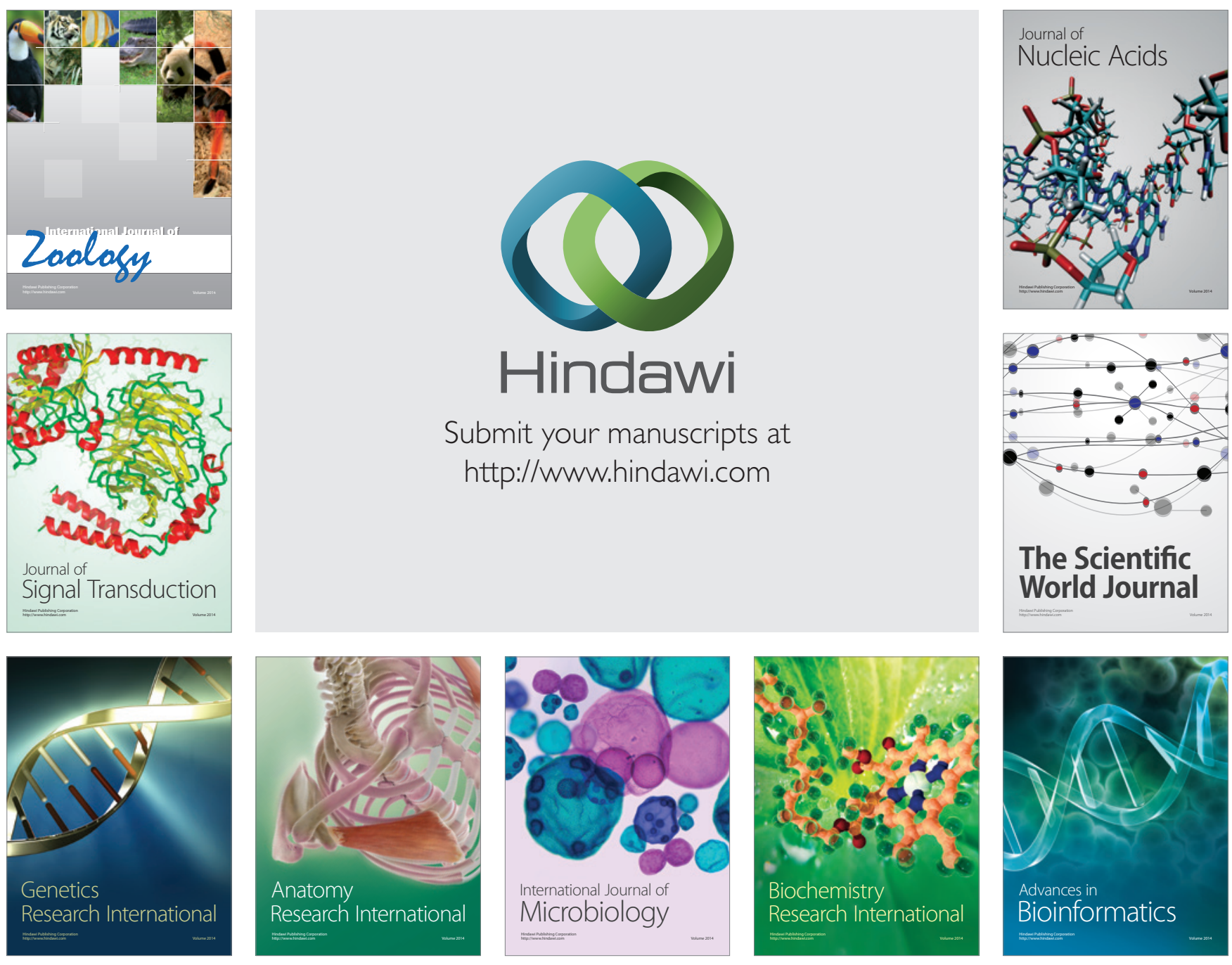

The Scientific World Journal
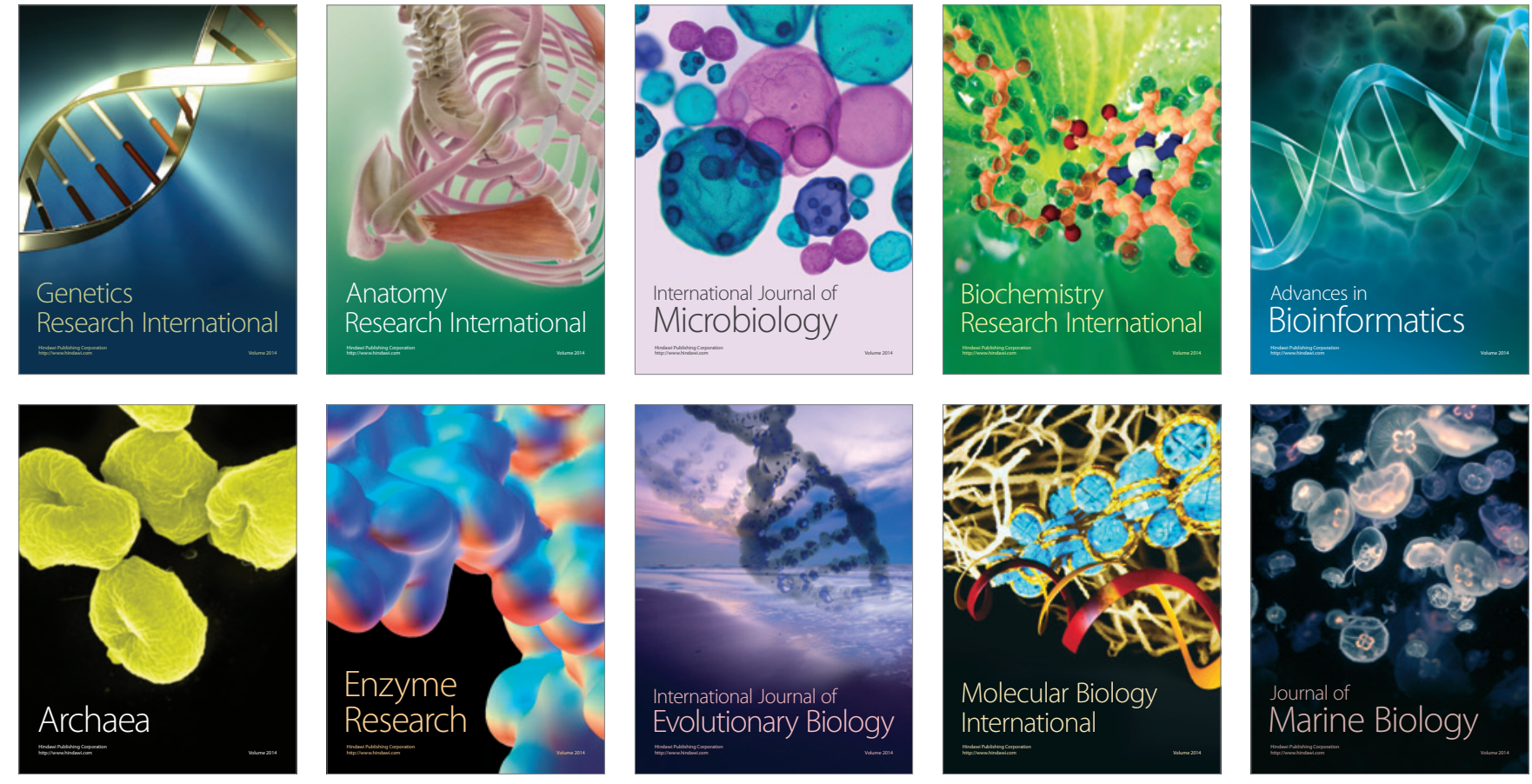